\title{
Insights into calcite growth inhibition mechanisms from calcium isotopes
}

LAURA NIELSEN LAMMERS AND JENNIFER V MILLS

University of California, Berkeley

Presenting Author: lnlammers@berkeley.edu

The development of predictive and mechanistic crystal growth models has traditionally relied on insights from a wide range of methods including kinetic experiments, imaging, spectroscopy, and computational chemistry. While isotopic approaches have received comparatively little attention, study of stable isotope fractionation during mineral growth provides information that is otherwise inaccessbile or ambiguous. Importantly, isotopic data give unique constraints on the gross fluxes of ions participating in growth, which can then be tied to specific surface properties and rate-limiting mechanisms. Calcite precipitated from natural fluids such as seawater inevitably contains significant amounts of non-stoichiometric metal cations that interact with the growing mineral surface, generally slowing growth. However, the mechanisms of growth rate inhibition by these impurity ions, and their impact on the preserved solid isotope composition, are debated.

Here we use calcium isotopes to isolate the specific processes that dominate classical calcite growth rate inhibition by both compatible (manganese) and incompatible (magnesium) impurity metal cations. Growth experiments were performed in a precisely controlled chemical environment for $\mathrm{Mn} / \mathrm{Ca} 0.001-0.15$ and $\mathrm{Mg} / \mathrm{Ca}=0.01-2.5$, and growth rate, metal partitioning, and calcium isotope fractionation were measured. Both $\mathrm{Mn}$ and $\mathrm{Mg}$ significantly inhibited the calcite growth rate by up to $93 \%$, but calcium isotope fractionation was completely invariant with growth rate in all experiments.

Applying an ion-by-ion model for calcite growth, this invariant $\Delta^{44 / 40} \mathrm{Ca}$ suggests that the presence of $\mathrm{Mn}$ or $\mathrm{Mg}$ does not significantly change the relative rates of $\mathrm{Ca}$ attachment and detachment at kink sites during growth. Thus, although extensive uptake of $\mathrm{Mn}$ (up to $65 \mathrm{~mol} \% \mathrm{MnCO}_{3}$ ) alters the thermodynamic stability of the solid, the growth rate and calcium surface exchange flux appear to be dominantly controlled by kink blocking and not by a solubility effect. These results imply that the calcium isotope compositions of abiogenically precipitated calcite can record aqueous calcite supersaturation conditions even in solutions with high $\mathrm{Mg} / \mathrm{Ca}$ ratios like seawater. 